\title{
ANALISIS KELAYAKAN USAHA PERKEBUNAN KURMA (STUDI KASUS KEBUN KURMA BARBATE KABUPATEN ACEH BESAR)
}

\author{
Analysis of Date Palm Plantation Bussiness Feasibility (Case Study of Kebun Kurma \\ Barbate Aceh Besar Regency)
}

\author{
Hanna Risa ${ }^{1}$, Edy Marsudi ${ }^{1}$, Azhar $^{1 *}$ \\ ${ }^{1}$ Program Studi Agribinis, Fakultas Pertanian, Universitas Syiah Kuala
}

\begin{abstract}
Abstrak. Kurma merupakan buah yang berasal dari Jazirah Arab. Kurma sudah berabad-abad lamanya dikonsumsi masyarakat di Timur Tengah, baik untuk makanan pokok maupun kudapan. Dewasa ini, kurma tidak hanya dikonsumsi oleh masyarakat di Timur Tengah saja namun oleh hampir seluruh masyarakat di Dunia, termasuk Indonesia. Pertumbuhan tingkat konsumsi kurma di Indonesia semakin meningkat pada setiap tahunnya, hal ini ditunjukkan oleh adanya permintaan impor kurma yang selalu meningkat pada setiap tahun. Pada akhir tahun 2015, Provinsi Aceh tepatnya Kabupaten Aceh Besar, mulai membudidayakan kurma. Tujuan dari penelitian ini yaitu untuk menganalisis kelayakan usaha perkebunan kurma di Aceh dilihat dari aspek pasar dan pemasaran serta aspek teknis dan teknologi dan aspek finansial. Hasil penelitian menunjukkan bahwa usaha perkebunan kurma pada Kebun Kurma Barbate layak dijalankan dari aspek pasar dan pemasaran serta aspek teknis dan teknologi. Dari aspek finansial, Kebun Kurma Barbate menunjukkan bahwa layak untuk diusahakan dilihat dari nilai NPV $=\mathrm{Rp} 12.796 .782 .763$, Net B/C $=9,10$, IRR $=43,81$ Persen, dan Payback Period $=5$ tahun 2 bulan. Analisis sensitivitas menunjukkan bahwa usaha perkebunan kurma tetap layak untuk dijalankan apabila terjadi perubahan peningkatan biaya operasional sebesar 10 persen namun produksi tetap, dan apabila terjadi penurunan produksi sebesar 10 persen namun biaya operasional tetap.
\end{abstract}

Kata Kunci : Kelayakan, Kurma.

Abstract. Date palm is fruit that come from the Arabian Peninsula. Dates have been consumed by people in the Middle East for centuries, both as a staple food and as a snack. Today, dates are not only consumed by people in the Middle East, but by almost all people in the world, including Indonesia. Growth in consumption rates for dates in Indonesia is increasing every year, this is indicated by the demand for date palm imports which always increases every year. At the end of 2015, the Province of Aceh, precisely in Aceh Besar District, began cultivating dates. The purpose of this research is to analyze the feasibility of date palm plantation business in Kebun Kurma Barbate in Aceh Besar District from the market and marketing aspects, technical and technological aspects, and financial aspects. The result show that the date palm plantation business in the Kebun Kurma Barbate is feasible from the market and marketing aspects, technical and technological aspects. From the financial aspect, Kebun Kurma Barbate shows that it is feasible, it is showed by NPV $=\mathrm{Rp}$ $12,796,782,763$, Net B / C $=9,10, \mathrm{IRR}=43,81$ Percent, and Payback Period $=5$ years 2 months. Sensitivity analysis shows that the date palm plantation business is still feasible if there is a change in operational costs by 10 percent but production remains, and if there is a production decline of 10 percent but the operating costs remain.

Keywords : Feasibility, date palm. 


\section{PENDAHULUAN}

Kurma merupakan salah satu pohon buah tertua di wilayah arab dan secara ekstensif dibudidayakan sebagai buah yang memiliki rasa manis yang dapat dikonsumsi oleh semua orang. Karena sudah sejak lama dibudidayakan, distribusi asli kurma tidak diketahui secara pasti namun diduga berasal dari suatu daerah di gurun Afrika Utara dan Asia Barat Daya (Baloch, 2014). Kurma telah menjadi makanan pokok bagi masyarakat di Timur Tengah selama ribuan tahun lamanya. Kurma dapat dikonsumsi oleh segala umur, baik anak-anak, dewasa, hingga lanjut usia. Dewasa ini, kurma tidak hanya dikonsumsi oleh masyarakat di Timur Tengah saja, namun juga oleh masyarakat di seluruh dunia, baik di Benua Asia, Eropa, Australia, Afrika, hingga Amerika. Negara penghasil kurma terbesar di dunia adalah Mesir dengan jumlah produksi kurma segar tahunan pada tahun 2017 mencapai 1.084.529 ton, kemudian diikuti oleh Iran dengan total produksi 947.809 ton, dan Arab Saudi dengan total produksi 836.983 ton (Worldatlas.com, 2017 ). Manickavasagan (2012) menyebutkan bahwa tiga negara pengimpor kurma terbesar di dunia pada tahun 2007 adalah India, Maroko, dan Perancis. Indonesia merupakan negara ketujuh yang mengimpor kurma paling banyak di dunia, yaitu dengan total impor sebesar 12.005 ton atau $2.5 \%$ dari total impor dunia dan bertambah sebanyak 2. 233 ton atau 14\% dari rentang tahun 2000-2007. Data valume impor kurma Indonesia secara lebih jelas dapat dilihat pada tabel di bawah ini.

Tabel 1. Volume dan Pertumbuhan Impor Buah Kurma Indonesia Tahun 2007-2016

\begin{tabular}{rcc}
\hline Tahun & Volume Impor $(\mathbf{K g})$ & Pertumbuhan $(\%)$ \\
\hline 2007 & 12.005 .643 & - \\
2008 & 13.907 .422 & 15,84 \\
2009 & 16.435 .573 & 18,18 \\
2010 & 16.985 .862 & 3,35 \\
2011 & 20.142 .151 & 18,58 \\
2012 & 22.557 .895 & 11,99 \\
2013 & 29.110 .599 & 29,05 \\
2014 & 30.530 .938 & 4,88 \\
2015 & 31.052 .857 & 1,71 \\
2016 & 33.228 .512 & 7,01 \\
\hline
\end{tabular}

Sumber : Badan Pusat Statistik, 2017

Pemerintah Indonesia melakukan impor kurma dari berbagai negara di dunia untuk memenuhi permintaan kurma yang tinggi. Hal ini terjadi karena Indonesia tidak memproduksi kurma di dalam negeri, sehingga harus didatangkan dari luar negeri. Sebagai negara yang agraris, Indonesia sebenarnya mampu untuk memproduksi kurma, sebagaimana yang dijelaskan oleh pakar buah dari Bogor yaitu Dr. Mohammad Reza Tirtawinata MS dalam infoagrobisnis.com, Indonesia sangat berpeluang untuk melakukan budidaya kurma tropis. Hal ini disebabkan karena kondisi dari agroklimat di Indonesia sangat mirip dengan Thailand yang sudah terlebih dulu melakukan budidaya kurma.

Pada tahun 2015, Indonesia telah melakukan budidaya kurma di Aceh tepatnya di Desa Data Makmur Kecamatan Blang Bintang Kabupaten Aceh Besar. Perkebunan kurma ini dinamai dengan Kebun Kurma Barbate. Kebun Kurma Barbate telah menanam pohon kurma dengan luas lahan sebanyak 3 hektar. Penelitian ini bertujuan untuk melihat kelayakan usaha perkebunan kurma dilihar dari aspek pasar dan pemasaran serta aspek teknis dan 
teknologi, aspek finansial, dan untuk melihat apakah masih usaha perkebunan kurma tetap layak dijalankan apabila terjadi perubahan biaya dan manfaat.

\section{Tempat dan Waktu Penelitian}

\section{METODE PENELITIAN}

Penelitian ini dilakukan di Kebun Kurma Barbate Desa Data Makmur Kecamatan Blang Bintang Kabupaten Aceh Besar. Waktu penelitian dilakukan pada bulan Juni dan Juli 2018.

\section{Objek dan Ruang Lingkup Penelitian}

Objek penelitian ini adalah petani kurma dengan ruang lingkup yang terbatas pada analisis kelayakan usaha perkebunan kurma di Desa Data Makmur Kecamatan Blang Bintang Kabupaten Aceh Besar.

\section{Metode Pengumpulan Data}

Data yang digunakan dalam penelitian ini terdiri dari data primer dan data sekunder. Data primer diperoleh dari hasil wawancara langsung dengan pemilik, yaitu Bapak Mahdi Muhammad dan tenaga kerja Kebun Kurma Barbate, sedangkan data sekunder diperoleh dari berbagai instansi yang berhubungan seperti Badan Pusat Statistik (BPS) serta dari kajian pustaka seperti buku, penelitian terdahulu dan dokumen.

\section{Model Analisis}

Tujuan pertama dianalisis menggunakan analisis deskriptif, yaitu untuk menganalisis kelayakan usaha perkebunan kurma dilihat dari aspek pasar dan pemararan serta aspek teknis dan teknologi.

Tujuan kedua dianalisis dengan metode kuantitatif dengan menggunakan kriteria investasi, yaitu Net Present Value, Net Benefit Cost Ratio, Internal Rate of Return, dan Payback Period.

1. Net Present Value

Net Present Value (NPV) adalah selisih antara Present Value Benefit dengan Present Value Cost selama proyek. NPV menunjukkan manfaat bersih yang diterima selama umur proyek pada tingkat discount factors tertentu.

$$
\mathrm{NPV}=\sum_{\mathrm{t}=1}^{\mathrm{n}} \frac{\mathrm{Bt}}{(1+i)^{t}}-\sum_{\mathrm{t}=1}^{\mathrm{n}} \frac{\mathrm{Ct}}{(1+i)^{t}}=\sum_{\mathrm{t}=1}^{\mathrm{n}} \frac{\mathrm{Bt}-\mathrm{Ct}}{(1+i)^{t}} \ldots \ldots \ldots \ldots \ldots . . . \mathrm{Su} \mathrm{w}^{\prime} \mathrm{ud}, 2006
$$

Keterangan :

$$
\begin{array}{ll}
\mathrm{NPV} & =\text { Nilai bersih sekarang (Rupiah) } \\
\mathrm{Bt} & =\text { Manfaat pada tahun ke-t (Rupiah) } \\
\mathrm{Ct} & =\text { Biaya pada tahun ke-t (Rupiah) } \\
\mathrm{n} & =\text { Umur proyek (tahun) } \\
\mathrm{i} & =\text { Tingkat suku bunga yang berlaku }(\%) \\
\mathrm{t} & =\text { Tahun }
\end{array}
$$

Dalam metode NPV terdapat tiga kriteria investasi, yaitu :

a. Jika NPV < 0, artinya usaha tidak layak untuk dilaksanakan.

b. Jika NPV $=0$, artinya usaha mampu memberikan tingkat pengembalian sebesar modal. Opportunity cost

c. Jika NPV >0, usaha layak untuk dilaksanakan. 
2. Net Benefit Cost Ratio

Net Benefit Cost Ratio (Net B/C) merupakan perbandingan antara jumlah net present value positif (sebagai pembilang) dan jumlah net present value negatif (sebagai penyebut).

$$
\text { Net } \mathrm{B} / \mathrm{C}=\frac{\sum_{t=1}^{n} \frac{B^{t}-C^{t}}{(1+i)^{t}}}{\sum_{t=1}^{n} \frac{B^{t}-C^{t}}{(1+i)^{t}}} \text { atau Net B/C }=\frac{\sum_{t=1}^{n}(N P V)(+)}{\sum_{t=1}^{n} N P V(-)} \ldots \ldots \ldots \ldots . . . \text { Pasaribu, } 2012
$$

Keterangan :

$$
\begin{array}{ll}
\mathrm{B}_{\mathrm{t}} & =\text { Benefit pada tahun ke- } \mathrm{t} \\
\mathrm{Ct} & =\text { Biaya pada tahun ke- } \mathrm{t} \\
\mathrm{i} & =\text { Tingkat suku bunga yang berlaku }(\%) \\
\mathrm{n} & =\text { Umur ekonomis proyek }
\end{array}
$$

Dalam metode ini terdapat tiga kriteria investasi yaitu :

a. Jika Net $\mathrm{B} / \mathrm{C}=1$, maka NPV $=0$, usaha layak untuk dijalankan, namun keuntungan hanya diperoleh sebesar Opportunity cost.

b. Jika Net $\mathrm{B} / \mathrm{C}<1$, maka NPV $<0$, usaha dikatakan tidak layak untuk dijalankan.

c. Jika Net B/C > 1, maka NPV > 0, usaha dikatakan layak untuk dijalankan.

3. Internal Rate of Return

Internal Rate of Return (IRR) merupakan alat ukur untuk mengetahui kemampuan proyek dalam mengembalikan bunga pinjaman dari lembaga internal keuangan yang membiayai proyek tersebut.

Keterangan :

$$
I R R=i_{1}+\frac{N P V_{1}}{N P V_{1}-N P V_{2}} \times\left(i_{2}-i_{1}\right) \ldots \ldots \ldots \ldots \ldots \ldots \ldots \ldots . . . \text { Su'ud, } 2006
$$

IRR = Tingkat internal hasil $(\%)$

$\mathrm{NPV}_{1}=$ Nilai NPV pada tingkat bunga i (positif menuju nol)

$\mathrm{NPV}_{2}=$ Nilai NPV pada tingkat bunga i (negatif menuju nol)

$\mathrm{I}_{1} \quad$ = Tingkat suku bunga $\mathrm{I}_{1}$ (dimana NPV positif)

$\mathrm{I}_{2} \quad=$ Tingkat suku bunga $\mathrm{I}_{2}$ (dimana NPV negatif)

Dalam metode IRR terdapat tiga kriteria kelayakan usaha, yaitu :

a. IRR < tingkat discount factor, maka usaha tidak layak untuk dijalankan.

b. $\quad$ IRR = tingkat discount factor, maka usaha tidak menguntungkan namun juga tidak merugikan.

c. IRR > tingkat discount factor, maka usaha layak untuk dijalankan.

4. Payback Period

Payback Period adalah periode modal kembali atau lamanya waktu yang diperlukan untuk mengembalikan investasi awal atau modal yang sudah dikeluarkan.

$$
\text { Payback Period }=\mathrm{T}_{\mathrm{p}-1}+\frac{\sum_{i=1}^{n} \overline{\mathrm{I}}-\sum_{i=1}^{n} \underline{\mathrm{B}}}{\mathrm{B}_{p}}
$$
Ibrahim, 2009

Keterangan :

$\mathrm{T}_{\mathrm{p}-1} \quad=$ Tahun sebelum terdapat Payback Period

$\overline{\mathrm{I}} \quad=$ Jumlah investasi yang telah di-discount 
$\mathrm{B}=$ Jumlah benefit yang telah di-discount sebelum Payback period

$\underline{\mathrm{B}}_{p} \quad=$ Jumlah benefit pada Payback period berada

Tujuan ketiga dianalisis menggunakan analisis sensitivitas, yaitu suatu analisis yang dilakukan untuk melihat apakah suatu usaha masih layak untuk dijalankan bila terjadi perubahan dalam dasar-dasar perhitungan biaya dan manfaat dengan menggunakan dua skenario yaitu:

1. Biaya operasional naik $10 \%$, produksi tetap.

2. Biaya operasional tetap, produksi turun $10 \%$.

\section{Asumi-asumsi yang Digunakan}

1. Umur ekonomis tanaman kurma adalah 50 tahun, sesuai dengan pernyataan AlKhayri (2015).

2. Harga bibit, alat, dan mesin berdasarkan standar harga yang berlaku pada saat penelitian.

3. Tingkat suku bunga yang berlaku adalah 11 persen berdasarkan besarnya suku bunga pinjaman pada Bank Rakyat Indonesia Syariah dan diasumsikan konstan hingga umur proyek bisnis berakhir.

4. Harga jual kurma yang berlaku pada penelitian ini yaitu Rp. 100.000/kg, mengikut kepada harga kurma varietas barhee rata-rata dan diasumsikan konstan hingga akhir umur ekonomis kurma.

5. Pada tahun ke 4 produksi kurma adalah $25 \mathrm{~kg} /$ pohon, tahun ke 5 adalah $50 \mathrm{~kg} /$ pohon, tahun ke 6 adalah $80 \mathrm{~kg} /$ pohon dan pada tahun ke 4 hingga tahun ke 50 produksi kurma adalah $120 \mathrm{~kg} /$ pohon.

\section{Gambaran Umum Lokasi Penelitian}

\section{HASIL PENELITIAN DAN PEMBAHASAN}

Kebun Kurma Barbate merupakan perkebunan kurma yang terletak di Desa Data Makmur Kecamatan Blang Bintang Kabupaten Aceh Besar. Perkebunan ini sudah ada sejak akhir tahun 2015. Luas perkebunan ini mencapai 14 hektar, namun belum semua dari lahan ditanami tanaman kurma. Pada akhir tahun 2015, dilakukan penanaman kurma sebanyak tiga hektar. Terbatasnya modal merupakan penyebab mengapa belum semua lahan ditanami tanaman kurma.

Kebun kurma Barbate yang terdapat pada penelitian ini merupakan milik seorang petani kurma yang bernama Mahdi Muhammad, S.E.,Ak. Kurma dibudidayakan karena kurma merupakan buah yang paling banyak disebutkan di dalam Al-quran, yaitu sebanyak 21 kali. Diantaranya terdapat pada QS Yaasin (36) : 34, QS Maryam (19) : 23, 25, QS AlKahfi (18) : 32, dan QS Al-Mu'minun (23) : 19.

\section{Syarat Tumbuh Tanaman Kurma}

1. Ketinggian Tempat

Tanaman kurma memiliki daya adaptasi yang tinggi, tumbuh dari dataran rendah hingga dataran tinggi. Thailand membudidayakan kurma dengan ketinggian yang bervariasi mulai dari 50-700 m dpl, diantaranya terdapat di Suphanburi, Ayutthaya, Nakhon, dan Chiangmai. Di lokasi-lokasi tersebut kurma berbuah dengan optimal, 
yaitu mampu berproduksi sebanyak $250 \mathrm{~kg}$ per pohon pada umur tujuh tahun (Apriyanti et al, 2015). Kondisi yang sama juga terdapat di Aceh Besar dimana Aceh Besar memiliki ketinggian dari 0-800 m dpl. Ketinggian tempat di Aceh Besar ini memenuhi syarat tumbuh dan produksi kurma.

2. Kualitas Tanah

Kurma dapat tumbuh dan berproduksi di berbagai jenis tanah, baik tanah yang sangat berpasir maupun tanah liat. Kurma sangat tahan pada kondisi tanah yang marginal, sebagimana selama ini ditunjukkan dengan tumbuh tegar di padang pasir, namun semakin subur tumbuh di Thailand, India, dan Amerika Serikat.

3. Suhu

Apriyanti et al (2015), menyebutkan bahwa kurma lazim dibudidayakan di daerah kering dan semi kering yang ditandai dengan musim panas yang panjang, tidak ada atau sangat sedikit hujan, dan tingkat kelembaban yang relatif sangat rendah selama periode pematangan buah. Meskipun kurma adalah jenis tanaman yang tumbuh optimal pada suhu $32-38^{\circ} \mathrm{C}$, namun kurma toleran pada rentang suhu yang panjang. BMKG mencatat Kabupaten Aceh Besar memiliki suhu rata-rata 23,4-31,30C sepanjang tahun 2017. Suhu udara tertinggi tercatat sebesar 37,20C pada tanggal 24 Juli 2017 dan suhu udara terendah tercatat sebesar 19,00C pada tanggal 19 Oktober 2017 di lokasi Stasiun Meteorologi Sultan Iskandar Muda Blang Bintang.

d. Curah Hujan

Curah hujan merupakan salah satu faktor penting syarat tumbuh dan produksi kurma, kurma lazim dibudidayakan di daerah yang memiliki rata-rata curah hujan tahunan $50 \mathrm{~mm}$. Dengan kondisi lingkungan yang kering, petani dapat memanen buah kurma pada fase rutab dan fase tamar langsung dari pohon. Hujan berpengaruh pada periode pembentukan buah. Fase rutab dan tamar merupakan tahap yang paling sensitif terhadap hujan, karena dapat menyebabkan buah busuk dan rontok.

e. Kelembaban Udara

Kelembaban udara berhubungan erat dengan curah hujan. Biasanya setelah terjadinya hujan, kelembaban udara juga akan meningkat. Kelembaban udara yang tinggi memicu perkembangan penyakit yang mengganggu tanaman seperti penyakit bercak daun oleh cendawan Graphiola phoenicis. Sementara pada kelembaban rendah, akan munculnya hama dan tungau.

f. Angin

Kecepatan angin berefek pada tanaman kurma muda dan efisiensi polinasi pada tanaman dewasa. Perakaran yang belum kuat membuat pohon yang masih muda rentan terhadap angin kencang. Angin lembut berguna dan membantu proses penyerbukan. Sementara angin berkecepatan tinggi akan meniup jauh serbuk sari, terutama pohon yang berada di pinggir kebun.

g. Cahaya

Sama dengan tanaman buah yang lain, pohon kurma membutuhkan cahaya matahari untuk proses fotosintesis. Kurma membutuhkan lama pencahayaan matahari yang panjang untuk bisa berbunga. Agar tumbuh dengan baik, diperlukan pencahayaan sekitar 16 jam sehari dengan intensitas 10.000-12.000 footcandle. Kondisi ini tercapai pada saat cuaca cerah dengan awan sedikit atau cuaca tidak mendung. 


\section{Aspek Pasar dan Pemasaran}

Beberapa hal yang dilihat pada aspek pasar dan pemasaran yaitu :

a. Potensi Pasar Kurma Dunia

Selama berabad-abad kurma menjadi santapan sehari-hari penduduk negeri padang pasir. Namun dewasa ini, konsumsi kurma tidak hanya berkembang di jazirah arab saja namun juga menyebar ke berbagai negara seperti Amerika, Rusia, Perancis, dan Indonesia. Semakin berkembanganya tradisi mengonsumsi kurma, kebutuhan terhadap kurma pun semakin meningkat. Worldatlas (2017) mencatat, Mesir merupakan negara penghasil kurma terbesar di dunia. Hasil produksinya mencapai 1.084.529 ton dengan estimasi 15.582 .000 pohon kurma. Dengan sentra penanaman di jazirah Arab kini kurma menjadi komoditas perdagangan dunia.

b. Potensi Pasar Kurma Indonesia

Indonesia merupakan negara kesembilan importir kurma terbesar di dunia pada tahun 2012 dengan total volume impor mencapai 22.557 ton atau senilai dengan Rp 251 miliar. Total impor kurma di Indonesia selalu meningkat pada setiap tahun, BPS mencatat volume impor di Indonesia mencapai hingga 31.052 ton pada tahun 2015 dan 33.228 ton pada tahun 2016. Pertumbuhan permintaan ini menunjukkan bahwa kurma memiliki serapan pasar yang tinggi sehingga membuka peluang masyarakat untuk membudidayakan kurma secara komersil.

Apriyanti et al (2015) mengungkapkan bahwa meningkatnya angka impor kurma Indonesia disebabkan kesadaran masyarakat terhadap kesehatan yang semakin membaik. Seiring berkembangnya teknologi, terungkap bahwa kurma memiliki banyak manfaat. Contohnya sirop kurma yang populer karena berkhasiat meningkatkan jumlah trombosit penderita demam berdarah. Selain itu, kurma juga dianjurkan untuk dikonsumsi pada perempuan yang baru melahirkan dan pasien pascaoperasi untuk mempercepat pemulihan.

c. Rencana Pemasaran

Kurma akan dipasarkan secara langsung maupun dengan menggunakan pasar online. Kemajuan teknologi terutama di bidang media sosial memudahkan petani untuk memasarkan produknya. Petani dapat bekerja sama dengan toko online untuk memasarkan produknya sehingga penjualan akan lebih mudah dan terjangkau hingga ke seluruh Indonesia.

Untuk persaingan pasar kurma, kurma yang berada di pasar Indonesia selama ini merupakan kurma yang di impor dari luar negeri. Indonesia belum mampu untuk memenuhi permintaan kurma. Selama ini masyarakat Indonesia hanya menanam kurma dalam skala kecil yaitu sebagai hobi. Kurma yang berbuah pun dalam jumlah yang sangat sedikit dan jumlah produksinya rendah. Sehingga usaha perkebunan kurma merupakan usaha yang sangat menjanjikan untuk dikembang jika dilihat dari banyaknya permintaan kurma pada setiap tahun.

\section{Aspek Teknis}

1. Lokasi perkebunan

Lokasi budidaya kurma ini terletak di Kecamatan Blang Bintang Kabupaten Aceh Besar, pemilihan lokasi ini didasarkan pada keadaan infrastruktur yang baik seperti adanya jalan yang bisa dilalui oleh kendaraan roda dua maupun roda empat, lokasi dekat dengan kota yaitu sekitar $13 \mathrm{~km}$ dari Bandara Internasional Sultan Iskandar 
Muda, dan lahan yang dibeli oleh petani cukup murah yaitu sekitar Rp. 50.000.000 hingga Rp. 100.000.000 per hektar, tergantung dari jarak lahan dengan jalan raya. Semakin dekat lahan dengan jalan raya maka semakin tinggi harga tanahnya.

2. Persiapan Lahan

Persiapan lahan kurma berupa pembersihan lahan budidaya tanaman kurma dari semak dan batu, pembuatan lubang tanam, dan membangun instalasi irigasi. Pembersihan lahan bertujuan agar tidak ada gangguan saat pengolahan tanah. Pohonpohon liar, semak belukar, serta sampah yang ada dibersihkan pada lahan yang akan ditanami tanaman kurma. Hal ini karena tanaman kurma memerlukan sinar matahari penuh untuk pertumbuhan dan produksinya. Selain itu, pembersihan lahan juga dilakukan untuk mencegah kontaminasi dari zat yang terkandung dalam sampah kaleng maupun plastik.

3. Pembibitan

Bibit yang digunakan pada kebun kurma ini merupakan bibit kultur jaringan yang didatangkan langsung dari laboratorium tissue culture di Inggris, yaitu Date Palm Development (DPD). Date Palm Development (DPD) merupakan salah satu laboratorium kultur jaringan kurma tertua di dunia dan merupakan pemasok bibit kurma yang dibudidayakan di Thailand yang terkenal dengan kurma tropisnya serta pemasok bibit kurma pada 30 negara di dunia termasuk negara-negara di Timur Tengah.

Varietas Bibit yang dibudidayakan oleh Kebun Kurma Barbate merupakan bibit varietas barhee, medjol, sukari, dan ajwa. Varietas barhee merupakan varietas yang paling banyak dibudidayakan oleh perkebunan kurma Barbate karena merupakan jenis kurma yang paling sesuai dengan iklim dan lahan di Indonesia. Varietas barhee yang berasal dari Irak ini memiliki bentuk bulat, bewarna kuning, berdaging buah tebal, dan memiliki rasa yang manis. Barhee memiliki produktivitas yang tinggi yaitu mencapai $350 \mathrm{~kg}$ per pohon. Jenis kurma ini merupakan jenis yang paling populer dikonsumsi dalam bentuk segar atau dalam bentuk khalal.

4. Pemanenan

Tanaman kurma mulai berbuah pada umur empat tahun. pada umur empat tahun, tanaman kurma dapat dipanen namun produksinya belum optimal. Tanaman kurma akan berproduksi optimal pada tahun ke 7 hingga tahun ke 50. Setelah umur tanaman kurma lebih dari 50 tahun, kurma masih menghasilkan buah namun dalam jumlah yang lebih kecil serta biaya perawatan yang lebih besar. Pemanenan kurma dilakukan satu tahun sekali. Kurma dipanen dalam tiga fase, yaitu fase khalal (buah segar), fase Aspek Finansial rutab (matang penuh), dan fase tamar (semi kering atau kering).

Aspek finansial adalah hal-hal yang menyangkut masalah keuangan yang diinvestasikan dalam sebuah usaha, terutama dalam hal rasio antara pengeluaran dengan penerimaan dari usaha tersebut (Pasaribu, 2012). Pengeluaran dalam penelitian ini adalah semua biaya yang dikeluarkan dalam usaha perkebunan kurma Barbate di Kabupaten Aceh Besar. Pengeluaran ini meliputi biaya investasi dan biaya operasional. Sedangkan penerimaan merupakan manfaat yang diperoleh oleh petani dari penjualan kurma. 


\section{Biaya Investasi}

Biaya investasi merupakan biaya yang dikeluarkan dari mulai usaha perkebunan kurma dijalankan hingga usaha kebun kurma menghasilkan. Biaya investasi yang dikeluarkan oleh perkebunan kurma Barbate terdiri dari pembelian lahan kurma, pembelian bibit, mesin dan peralatan, listrik dan air, pemupukan, penyulaman, dan perawatan pada tiga tahun pertama.

Total biaya investasi pada tahun petama yang dikeluarkan oleh perkebunan kurma Barbate adalah sebesar Rp 1.144.925.000 atau Rp 381.641.667 per hektar. Biaya investasi terbesar dikeluarkan untuk membeli bibit dan lahan. Total biaya investasi yang dikeluarkan oleh kebun kurma Barbate pada tahun kedua adalah Rp 286.800.000 atau Rp 95.600.000 per hektar. Sedangkan pada tahun ketiga, total biaya investasi yang dikeluarkan oleh Kebun Kurma Barbate pada tahun ketiga yaitu Rp 430.800.000 atau Rp 143.600.000 per hektar.

\section{Biaya Operasional}

Biaya operasional dikeluarkan ketika tanaman kurma mulai berproduksi. Komponen biaya operasional yang dikeluarkan oleh perkebunan kurma Barbate yaitu biaya panen, biaya perawatan, biaya listrik dan air, biaya tenaga kerja, biaya pergantian alat dan mesin, biaya penyusutan, serta zakat.

Biaya panen yaitu biaya yang dikeluarkan untuk memanen buah kurma. Biaya panen ini dihitung berdasarkan banyaknya tanaman kurma yang dipanen. Kurma yang dipanen merupakan kurma betina yang jumlahnya adalah 300 pohon. Tahun ke 4 hingga ke 6 , satu pohon kurma dipanen dengan biaya Rp 50.000 per pohon, sedangkan pada tahun ke 7 hingga ke 15 biaya panen naik menjadi Rp 100.000 per pohon, pada tahun ke 16 hingga ke 25 biaya panen sebesar Rp 150.000 per pohon, dan pada tahun ke 26 hingga ke 50 biaya panen naik menjadi Rp 200.000 per pohon. Kenaikan biaya panen yang terus bertambah ini dikarenakan pohon kurma yang terus bertambah tinggi.

Biaya perawatan merupakan biaya yang dikeluarkan untuk merawat tanaman kurma yang sudah mulai berproduksi. Biaya perawatan ini mencakup biaya untuk pembersihan tanaman kurma dari gulma, biaya penyiraman, biaya pemupukan dan biaya pembelian pupuk, biaya piringan, biaya pemangkasan, biaya bahan bakar kendaraan, dan biaya keamanan. Biaya perawatan akan meningkat sebesar 15 persen dari total biaya perawatan sebelumnya setiap 10 tahun.

Biaya pergantian alat dan mesin yaitu biaya yang digunakan untuk mengganti alat dan mesin yang sudah lama dengan mesin dan alat yang baru karena telah habis masa ekonomisnya. Alat dan mesin yang diganti yaitu mesin potong rumput, mesin air, kendaraan roda empat, kendaraan roda tiga, kendaraan roda dua, cangkul, gunting, dan sekop yang masing-masing umur ekonomisnya adalah lima tahun. Sedangkan pagar, parit, dan jalan, biaya dikeluarkan untuk direhabilitasi dan dibersihkan. Kendaraan yang digunakan pada perkebunan ini merupakan kendaraan bekas pakai yang masih layak namun harganya lebih terjangkau.

Perkebunan kurma Barbate akan mengelurkan zakat pada setiap tahunnya sebesar sepuluh persen. Besarnya pengeluaran zakat ini didasarkan pada perintah yang terdapat di dalam kitab suci Agama Islam. 


\section{Penerimaan}

Penerimaan diperoleh dari hasil penjualan kurma. Hasil penjualan kurma tergantung pada produksi yang dihasilkan tanaman kurma. Produksi tanaman kurma didapatkan dari proyeksi dari tahun ke 4 hingga tahun ke 50.

a. Jumlah produksi

Tanaman kurma mulai berproduksi pada tahun ke 4 setelah tanam. Pada tahun pertama berproduksi, tanaman kurma akan dapat menghasilkan buah kurma dengan rata-rata $25 \mathrm{~kg}$ per pohon. Jumlah ini didasarkan pada keadaan pohon kurma yang masih kecil sehingga buah yang dihasilkan pun masih relatif sedikit. Pada tahun kedua berproduksi, tanaman kurma sudah mampu berproduksi dengan rata-rata 50 $\mathrm{kg}$ per pohon dan pada tahun ketiga produksi kurma naik menjadi $80 \mathrm{~kg}$ per pohon. Kemudian jumlah ini akan terus meningkat hingga pada tahun ke 7 setelah tanam tanaman kurma mampu berproduksi optimum, yaitu sekitar $120 \mathrm{~kg}$ per pohon. Jumlah pohon yang berproduksi dari lahan 3 hektar adalah 300 pohon.

Tanaman kurma akan terus berproduksi optimum hingga umurnya mencapai 50 tahun. Setelah berumur lebih dari 50 tahun, tanaman kurma masih mampu berproduksi namun jumlah produksinya sudah berkurang dan biaya perawatannya akan semakin besar. Kurma dipanen sekali dalam satu tahun.

b. Harga jual

Harga jual kurma yang digunakan pada penelitian ini yaitu Rp 100.000 per kg. Harga jual ini mengikut kepada harga jual rata-rata kurma varietas barhee.

\section{Analisis Kriteria Investasi}

Kriteria investasi digunakan untuk menilai suatu usaha layak atau tidak untuk dijalankan. Apabila suatu usaha layak untuk dijalankan, maka usaha yang dijalankan akan mampu memberikan manfaat (benefit) bagi pengusahanya. Dalam penelitian ini, kriteria investasi yang digunkan yaitu Net Present Value (NPV), Net Benefit Cost Ratio (Net B/C), Internal Rate of Return (IRR), dan Payback Period. Discount factor juga digunakan untuk mencari nilai masa sekarang dan nilai di masa akan datang. Tingkat discount factor yang digunakan yaitu sebesar 11 persen.

Tabel 2 . Hasil Analisis Kriteria Investasi Perkebunan Kurma Barbate

No Kriteria Investasi Hasil Penilaian pada DF

$11 \%$

\begin{tabular}{ccc}
\hline 1 & NPV & Rp 12.796 .782 .762 \\
2 & Net B/C & 9,83 \\
3 & IRR & $30 \%$ \\
4 & Payback Period & 5 tahun 2 bulan \\
\hline
\end{tabular}

Sumber : Data Primer (diolah), 2018

Net Present Value merupakan selisih antara benefit (manfaat) dengan cost (biaya) pada discount factor tertentu. hasil analisis menunjukkan NPV positif sebesar Rp 12.796.782.762, suatu usaha dapat dikatakan layak untuk dijalankan apabila nilai NPV >0, dengan demikian maka usaha perkebunan kurma Barbate layak untuk dijalankan karena $\mathrm{NPV}>0$. 
Net Benefit Cost Ratio merupakan perbandingan antara jumlah NPV positif dengan jumlah NPV negatif. Usaha akan dikatakan layak apabila Net B/C > 1. Nilai Net B/C yang diperoleh pada perkebunan kurma Barbate adalah 9,83yang artinya setiap tambahan yang dikeluarkan sebesar Rp 1 akan menghasilkan tambahan manfaat bersih bagi Kebun Kurma Barbate sebesar Rp 9,83. Hasil Net B/C menunjukkan bahwa Net B/C bernilai lebih dari satu yang artinya bahwa usaha perkebunan kurma Barbate layak untuk dijalankan.

Analisis IRR bertujuan untuk mengetahui seberapa besar pengembalian bisnis untuk terhadap investasi yang telah ditanamkan. IRR adalah suatu tingkat discount factor yang menghasilkan net present value sama dengan nol. Usaha dikatakan layak apabila IRR lebih besar daripada discount factor yang berlaku. Pada usaha perkebunan kurma Barbate didapatkan hasil IRR sebesar 30 persen, dimana nilai ini lebih besar dibandingkan tingkat discount factor yang digunakan pada penelitian ini yaitu 11 persen. Dari nilai IRR tersebut bahwa usaha perkebunan kurma Barbate layak untuk dijalankan.

Payback period adalah jangka waktu tertentu yang menunjukkan terjadinya arus penerimaan (in flow) secara kumulatif sama dengan jumlah investasi dalam bentuk present value. Payback period yang diperoleh selama 5 tahun 2 bulan bulan menunjukkan jangka waktu pengembalian investasi yang dilakukan lebih cepat dari umur ekonomis tanaman kurma yaitu 50 tahun. Dari nilai tersebut dapat diketahui bahwa usaha perkebunan kurma Barbate layak untuk dijalankan.

\section{Analisis Sensitivitas}

Analisis sensitivitas dilakukan untuk melihat kemungkinan-kemungkinan yang terjadi dengan hasil analisis suatu usaha jika terdapat perubahan dalam dasar-dasar perhitungan biaya dan manfaat. Dalam analisis ini, setiap kemungkinan harus diuji karena analisis suatu usaha didasarkan pada proyeksi-proyeksi yang mengandung banyak ketidakpastian tentang apa yang akan terjadi di masa akan datang.

Pada penelitian ini, analisis sensitivitas didasarkan pada adanya perubahan biaya operasional dan produksi. Adapun kemungkinan-kemungkinan yang akan dianalisis pada penelitian ini adalah :

1. Biaya operasional naik sebesar $10 \%$ sedangkan produksi tetap. Maka nilai yang diperoleh pada kriteria investasi yaitu :

a. Net Present Value (NPV) = Rp 12.235.646.652

b. Net Benefit Cost Ratio $(\mathrm{Net} \mathrm{B} / \mathrm{C}) \quad=9,24$

c. Internal Rate of Return (IRR) $=29$ persen

d. Payback Period = 5 tahun 2 bulan

Dari hasil analisis dapat dilihat bahwa nilai NPV $>0$, Net B/C $>1$, IRR $>$ dari tingkat suku bunga yang berlaku, dan payback period lebih cepat pengembalian investasi dibandingkan umur ekonomis kurma, maka dapat ditarik kesimpulan bahwa usaha perkebunan kurma Barbate tetap layak dijalankan jika terjadi kenaikan biaya operasional sebesar 10 persen namun produksi tetap.

2. Biaya operasional tetap sedangkan produksi turun sebesar $10 \%$.

a. Net Present Value (NPV) = Rp 10.798.044.923

b. Net Benefit Cost Ratio $(\mathrm{Net} \mathrm{B} / \mathrm{C}) \quad=8,21$

c. Internal Rate of Return (IRR) $\quad=26$ persen

d. Payback Period = 5 tahun 4 bulan 
Hasil analisis sensitivitas menunjukkan bahwa NPV $>0$, Net $B / C>1$, IRR $>$ dari tingkat suku bunga yang berlaku, dan payback period lebih cepat pengembalian investasi dibandingkan umur ekonomis kurma, maka dapat ditarik kesimpulan bahwa usaha perkebunan Kurma Barbate masih tetap layak dijalankan apabila terjadi penurunan produksi (benefit) sebesar 10 persen.

\section{Kesimpulan}

\section{KESIMPULAN DAN SARAN}

Berdasarkan hasil penelitian dan pambahasan dapat diambil simpulan :

1. Berdasarkan hasil analisis kelayakan usaha pada aspek non finansial, usaha perkebunan kurma Barbate layak untuk dijalankan dari aspek pasar dan pemasaran serta aspek teknis. Kelayakan sspek pasar ditunjukkan dari jumlah permintaan kurma yang selalu meningkat pada setiap tahun, meningkatnya kesadaran masyarakat akan manfaat kurma, dan masih kurangnya pesaing produsen kurma yang terdapat di dalam negeri. Dari aspek teknis ditujukkan dari kesesuaian lahan dan iklim dengan syarat tumbuh kurma, lokasi perkebunan dekat dengan perkotaan, serta teknologi yang digunakan sudah baik.

2. Hasil analisis kriteria investasi menunjukkan bahwa usaha Kebun Kurma Barbate layak dijalankan dari aspek finansial. Hal ini ditunjukkan dari nilai NPV >0, Net $\mathrm{B} / \mathrm{C}>1$, IRR $>$ tingkat suku bunga yang berlaku, dan payback period yang lebih cepat pengembalian biaya investasi dibandingkan umur ekonomis tanaman kurma.

3. Hasil analisis sensitivitas menunjukkan bahwa usaha Kebun Kurma Barbate tetap layak dijalankan apabila terjadi kenaikan biaya operasional sebesar 10\% sedangkan produksi tetap dan apabila biaya operasional tetap namun produksi turun sebesar $10 \%$..

\section{Saran}

Berdasarkan hasil penelitian dapat diberikan saran :

1. Hasil penelitian menunjukkan bahwa usaha perkebunan kurma Kebun Kurma Barbate layak untuk dijalankan, maka disarankan agar petani kurma dapat meminimalkan pengeluaran biaya perawatan agar memperoleh pendapatan yang lebih meningkat.

2. Dari penelitian ini menunjukkan bahwa usaha perkebunan kurma sangat menguntungkan untuk diusahakan secara komersil, diharapkan kepada pemerintah untuk mensosialisasikan cara budidaya tanaman kurma kepada masyarakat sehingga lebih banyak masyarakat membudidayakan kurma.

3. Penelitian ini masih tebatas pada analisis kelayakan usaha dengan menggunakan analisis kriteria investasi dan analisis sensitivitas, sehingga perlu penelitian selanjutnya untuk meneliti prospek pengembangan tanaman kurma di Aceh maupun di Indonesia.

\section{DAFTAR PUSTAKA}

Ahmad, I. 2015. Analisis Kelayakan Usaha Investasi pada Usaha Perkebunan Kelapa Sawit Rakyat di Desa Bambaira Kecamatan Bambaira Kabupaten Mamuju Utara. Jurnal Agrotekbis, Vol. 3, No. 3 : 381-389. 
Al-Abbad, A. 2011. A Study on the Economic Feasibility of Date Palm Cultivation in the Al-Hassa Oasis of Saudi Arabia. Journal of Development and Agricultural Economics Vol.3, No.9: 463-468.

Al-Khayri, J.M., Shri Mohan Jain, dan Dennis V. Johnson. 2015. Date Palm Genetic Resources and Utilization Volume 2: Asia and Europe. Springer, London.

Apriyanti, R.N., Eny Pujiastuti, dan Desi Sayyidati Rahimah. 2015. Kurma dari Gurun ke Tropis. Trubus Swadaya, Jakarta.

Badan Meteorologi Klimatologi dan Geofisika (BMKG). 2018. Provinsi Aceh Masuk Awal Musim Kemarau Januari-Juni. https://www.bmkg.go.id/berita/provinsi-aceh-masukawal-musim-kemarau-januari-juni. Diakses tanggal 19 Agustus 2018.

Baloch, J. 2014. Economics of Date Palm (Phoenix dactifera L.) Production and Its Development in District Kech, Balochistan Province of Pakistan. Journal of Economics and Suistanable Development, Vol.5, No.22.

Food and Agriculture Organization of The United Nations. 2000. Study of The Main European Markets for Dates and of The Commercial Potential of Non-traditional Varieties. FAO.

Hamali, A. 2016. Pemahaman Strategi Bisnis dan Kewirausahaan. Kencana, Jakarta.

Ibrahim, Y. Studi Kelayakan Bisnis Edisi Revisi. 2009. Rineka Cipta, Jakarta.

Infoagribisnis.com. 2017. Prospek Cerah Budidaya Kurma di Indonesia. https://www.infoagribisnis.com/2017/08/budidaya-kurma/. Diakses tanggal 19 Maret 2018.

Jain, S.M., Jameel M. Al-Khayri, dan Dennis V. Johnson. 2011. Date Palm Biotechnology. Springer, London.

Kasmir dan Jakfar. 2012. Studi Kelayakan Bisnis. Edisi Revisi. Kencana, Jakarta.

Manickavasagan, A., Mohammed Essa, dan Sukumar. 2012. Dates Peoduction, Processin, Food, and Medical Values. CRC, United State of America.

Nurmalina, R. 2010. Studi Kelayakan Bisnis. Institut Pertanian Bogor, Bogor.

Pasaribu, A. M. 2012. Kewirausahaan Berbasis Agribisnis. Andi Offset, Yogyakarta.

Pasaribu, A. M. 2012. Perencanaan dan Evaluasi Proyek Agribisnis. Lily Publisher, Yogyakarta.

Satuhu, S. 2010. Kurma, Khasiat, dan Olahannya. Penebar Swadaya, Jakarta.

Su'ud, M. H. 2006. Manajemen Agribisnis dalam Perspektif Pendekatan Sistem. Yayasan Mitra Cendikia, Banda Aceh.

Sudhersan, C. 2013. Date Palm Cultivar Specific Susceptibility to Grater Date Moth Infestation. Journal of American-Eurasian Suistanable Agriculture, Vol.7, No.1: 32-36.

Worldatlas.com. 2017. Leading Countries Growing Dates (Fresh Date Palm Fruits). https://www.worldatlas.com/articles/world-leading-countries-growing-freshdates.html. Diakses tanggal 19 Maret 2018.

Zaid, A. 2002. Climatic Requirements of Date Palm. Food and Agriculture Organization of United Nations, Italy. 